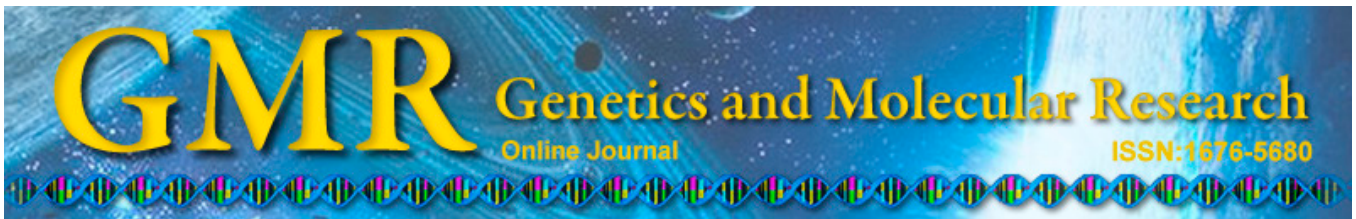

\title{
Fructus polygoni orentalis extract inhibited liver regeneration and proliferation of bone marrow cells of rat after partial hepatectomy
}

\author{
J.Y. Yang ${ }^{1}$, J.S. Wang ${ }^{1}$ and H.B. Liu ${ }^{2}$ \\ ${ }^{1}$ College of Physical Education, Henan Normal University, Xinxiang, \\ Henan Province, China \\ ${ }^{2}$ College of Life Science, Henan Normal University, Xinxiang, Henan Province, \\ China \\ Corresponding author: J.Y. Yang \\ E-mail: 041146@htu.cn
}

Genet. Mol. Res. 14 (3): 7671-7679 (2015)

Received September 16, 2014

Accepted January 26, 2015

Published July 13, 2015

DOI http://dx.doi.org/10.4238/2015.July.13.12

\begin{abstract}
To study the effect of fructus polygoni orentalis extract (EFPO) on liver regeneration and proliferation of bone marrow cells on rat model of partial hepatectomy, EFPO was extracted, and 60 adult male Wistar rats were divided randomly into 6 experimental groups. Rats were treated with intergastric administration (ig) with EFPO daily. All rats were euthanized 7 days after administration, and the livers and bone marrow cells were collected. The levels of taxifolin and quercetin in EFPO were 1.238 and $0.381 \mathrm{mg} / \mathrm{g}$, respectively. EFPO decreased the proliferating cell nuclear antigen expression of the regenerating liver. Obvious tissue damage was observed in the EFPO groups, such as a widened hepatic sinusoid cavity, several enlarged nuclei, slightly ballooning degeneration, and spotty and focal necrosis as compared to the control group. Additionally, 1.8 and $3.6 \mathrm{~g} / \mathrm{kg}$ EFPO significantly inhibited proliferating cell nuclear antigen expression in bone marrows cells $(P<0.05)$, and induced gathering of these cells during the $\mathrm{G}_{\mathrm{O}} / \mathrm{G}_{1}$ phases $(\mathrm{P}<0.05)$. The karyocyte and myelosis of bone marrows cells clearly
\end{abstract}


decreased, and mature erythrocytes increased $(\mathrm{P}<0.05)$ in the EFPO groups. Additionally, $3.6 \mathrm{~g} / \mathrm{kg}$ EFPO induced active proliferation, while the sham operation and control groups showed apparent active myeloproliferation. The maximum dosage of mice ig EFPO was $148.8 \mathrm{~g} / \mathrm{kg}$. Our results indicate that EFPO inhibits rat liver regeneration and bone marrow cell proliferation in regenerating rat liver.

Key words: Bone marrow cells proliferation; Fructus polygoni orientalis; Hepatocyte proliferation; Liver regeneration; Rat

\section{INTRODUCTION}

Fructus polygoni orientalis, named in Dian Nan Ben Cao in 1436 A.D. and recorded in the Pharmacopoeia of China 1997 edition, is a well-known herbal drug in Traditional Chinese Medicine (TCM). It is the fruit of the Polygonum orientale L. [(P. orientale), (Polygonaceae)] and has been used to treat various diseases including cirrhosis, hepatitis $\mathrm{B}$, and liver cancer (The Editorial Committee of "Zhong Hua Ben Cao", 1999) in folk medicine in China. The major antitumor components, texifolin and quercetin (Kuroyanagi and Fukushima, 1982; Xie et al., 2005), are flavonoids that can scavenge free radicals and have antimicrobial, antithrombotic, and anticarcinogenic activities (Bautista-Ortín et al., 2007; Makris et al., 2007; Tu et al., 2007). Although fructus polygoni orientalis is thought to be effective for treating liver diseases in Chinese folk medicine, only a few preliminary studies have examined this herb, and studies on using this herb to treat liver diseases have not been reported. In this study, we explored the effect of fructus polygoni orientalis extract on liver regeneration and the proliferation of bone marrow cells in a rat model of partial hepatectomy $(\mathrm{PH})$.

\section{MATERIAL AND METHODS}

\section{Animals and administration}

Adult male Wistar rats weighing 250-300 g were purchased from the Experimental Animal Center of Henan Normal University and provided with a diet of pellets and water $\mathrm{ad}$ libitum. The experiments involving rats were conducted according to the guidelines of the Animal Ethics Committee, Henan Province Animal Institute, China. Sixty Wistar rats were randomly divided into 6 experimental groups $(\mathrm{N}=10$ mice in each group), including a sham operation (SO) group and 2/3 PH group as described by Higgins et al. (1931), and then divided into a control group, cyclophosphamide (CTX) group, and 0.9, 1.8, and $3.6 \mathrm{~g} / \mathrm{kg}$ EFPO groups. Excluding the SO and control groups, rats were administrated intergastrically (ig) with $0.9 \%$ $\mathrm{NaCl}$, and CTX and EFPO groups ip with $0.03 \mathrm{~g} / \mathrm{kg} \mathrm{CTX}$ and $i g$ 0.9, 1.8 , and $3.6 \mathrm{~g} / \mathrm{kg} \mathrm{EFPO}$ daily, respectively. The rats were euthanized, and the liver and thighbone were placed on ice for further experiments after 7 days.

\section{Plant material extraction and sample preparation}

Fructus polygoni orientalis was purchased from a drugstore and authenticated by $\mathrm{Hu}$ Benxiang, Pharmacognosy Professor at the of College of Pharmacy, Shaanxi University of 
Chinese Medicine, and was consistent with the standard of China Pharmacopoeia. After the powder of dried fruits was immersed in water for $30 \mathrm{~min}$, the sample was extracted by heating and refluxing in the water bath thrice for $2 \mathrm{~h}$ each time. The content of texifolin and quercetin was determined by high-performance liquid chromtography on an Agilent TC-C ${ }_{18}$ column (4.6 x $250 \mathrm{~mm}, 5-\mu \mathrm{m}$ ) (Santa Clara, CA, USA), and eluted with a gradient elution of methanolwater containing $0.1 \%$ phosphoric acid. The flow rate was $1 \mathrm{~mL} / \mathrm{min}$, and the column temperature was set at $25^{\circ} \mathrm{C}$. The extract was concentrated using a rotary evaporator to $1 \mathrm{mg} / \mathrm{mL}$, and then stored at $4^{\circ} \mathrm{C}$. EFPO concentrations of $0.9,1.8$, and $3.6 \mathrm{~g} / \mathrm{kg}$ were obtained using gradient dilution prior to use.

\section{Histopathological analysis and immunohistochemistry}

Liver tissue samples were collected and fixed in $4 \%$ formaldehyde, processed routinely, and paraffin-embedded. Serial sections were stained with hematoxylin and eosin and immunohistochemistry (IHC) was used for histological analysis. For IHC, after paraffin removal and microwave-based antigen retrieval, endogenous peroxides' activity was eliminated, and non-specific binding was blocked. The slides were incubated with proliferating cell nuclear antigen (PCNA) primary antibody (Santa Cruz Biotechnology, Inc., Santa Cruz, CA, USA; dilution, 1:500) at $4^{\circ} \mathrm{C}$ overnight, and then with goat anti-mouse secondary antibody (Zhongshan Goldbridge, Nanjing, China). The specimens were then incubated with diaminobenzidine peroxidase substrate (Beijing Solarbio. Co. Ltd., Beijing, China) for brown staining and then subsequently counterstained with hematoxylin. All sections were observed under a microscope (Nikon eclipse, E100, Tokyo, Japan).

\section{Liver index}

Following treatment as described above, the body weight and livers were weighed and then used to calculate the liver index.

\section{Bone marrow biopsy and proliferation}

Following treatment as described above, the thighbone was removed, and marrow cavity was opened. The red marrow was exposed and imprinted on a clean glass slide. The imprints were dried in air, stained with Giemsa-Wright's solution for $20 \mathrm{~min}$, and examined by microscopy.

\section{Isolation of bone marrow cells (BMCs) and IHC}

Following treatment as described above, the thighbone was removed, and the marrow cavity was flushed with phosphate-buffered saline (PBS) on ice. The single cell suspension with RPMI-1640 containing 1\% fetal serum was smeared on clean glass slips, and PCNA expression was detected.

\section{Cell cycle of bone marrow mononuclear cells analysis by fluorescence correlation microscopy}

Bone marrow mononuclear cells were isolated by density gradient centrifugation and 
then analyzed by fluorescence correlation microscopy. Briefly, BMCs were centrifuged on $60 \%$ Percoll (Pharmacia Biotech, Uppsala, Sweden) at $1500 \mathrm{rpm}$ for $20 \mathrm{~min}$. Bone marrow mononuclear cells were washed in $4^{\circ} \mathrm{C}$ PBS, $\mathrm{pH} 7.4$, and cell viability was tested by trypan blue staining. The bone marrow mononuclear cells were fixed on ice with $100 \%$ alcohol and stained with propidium iodide (Sigma, St. Louis, MO, USA) solution containing $50 \mathrm{mg} / \mathrm{L}$ propidium iodide and $50 \mathrm{mg} / \mathrm{L} \mathrm{RNase}$ in PBS at room temperature in the dark for $30 \mathrm{~min}$. The samples were analyzed by flow cytometry (BD FACSCalibur, Franklin Lakes, NJ, USA) and analyzed using the Multicycle software.

\section{Acute toxicity experiment}

After administration $i g$ of the disposable maximum dosage to 10 Kunming healthy mice, their movement, excrement, water, and food consumption as well as body weight were observed and recorded for 7 days.

\section{Data analysis}

The 2-tailed Student $t$-test was employed to assess the significance of the data. The data are reported as the means \pm standard deviation. Values of $\mathrm{P}<0.05$ were considered to be statistically significant.

\section{RESULTS}

\section{Active ingredients}

EFPO was extracted by heating and refluxing in a water bath, and the contents of texifolin and quercetin were found to be 1.238 and $0.381 .1 \mathrm{mg} / \mathrm{g}$, respectively.

\section{EFPO inhibited liver cell proliferation}

The IHC results showed that PCNA expression in the control group (76.56 \pm 14.50$)$ was higher than that in the SO group $(66.24 \pm 9.37, \mathrm{P}<0.05)$, and the expression in $3.6 \mathrm{~g} /$ $\mathrm{kg}$ EFPO $(67.41 \pm 10.06)$ and CTX $(62.88 \pm 9.45)$ groups were lower than that in the control group $(\mathrm{P}<0.05, \mathrm{P}<0.01$, respectively), while $0.9 \mathrm{~g} / \mathrm{kg}$ EFPO $(74.48 \pm 12.27)$ and $1.8 \mathrm{~g} / \mathrm{kg}$ $(72.70 \pm 5.97)$ showed no clear differences. This indicated that $\mathrm{PH}$ activated liver regeneration, and EFPO could inhibit liver cell proliferation.

\section{EFPO inhibited liver repair}

After administration for 7 days, in addition to the $\mathrm{SO}$ group, the liver index and body weight in the other groups decreased. Compared to the control group, the change in body weight and liver index in the $3.6 \mathrm{~g} / \mathrm{kg}$ EFPO group significantly decreased $(\mathrm{P}<0.01)$; however, there was no clear effect on the residual liver. The change in body weight in the 3.6 and $1.8 \mathrm{~g} / \mathrm{kg}$ EFPO groups were lower than that in the control group $(\mathrm{P}<0.05)$, and the change in body weight in $0.9 \mathrm{~g} / \mathrm{kg}$ EFPO group was higher than that in the control group $(\mathrm{P}<0.05)$. This indicates that EFPO delayed the liver repair of the PH rats, and 3.6 and $1.8 \mathrm{~g} / \mathrm{kg} \mathrm{EFPO}$ 
decreased the body weight of PH rats, whereas the $0.9 \mathrm{~g} / \mathrm{kg}$ EFPO increased the body weight (Figure 1).

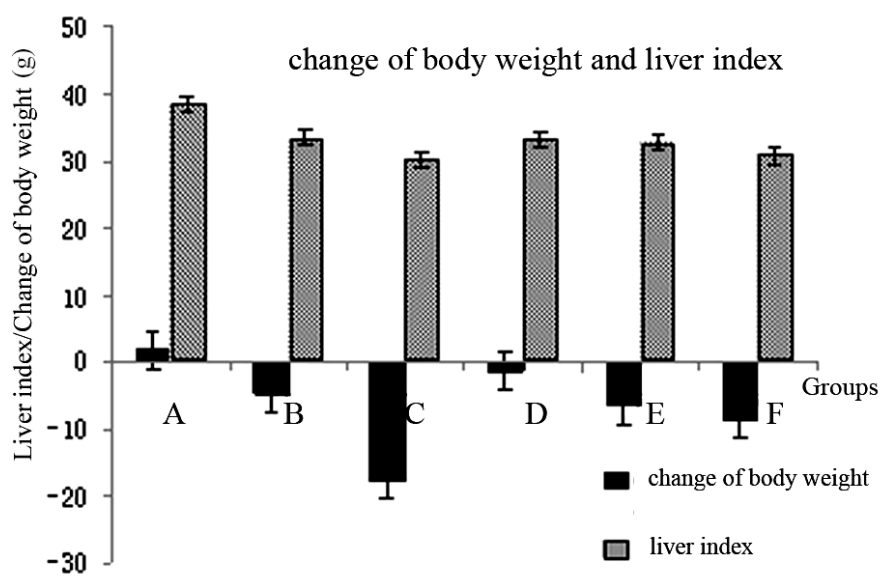

Figure 1. Effect of fructus polygoni orentalis extract (EFPO) on changes in body weight and liver index rats after partial hepatectomy $(\mathrm{PH})$. EFPO delayed the liver repair of $\mathrm{PH}$ rats, while 3.6 and $1.8 \mathrm{~g} / \mathrm{kg}$ EFPO reduced the body weight of rats with PH. A, B, C, D, E, and F represent the sham operation (SO), control, cyclophosphamide (CTX), and 0.9, 1.8, and $3.6 \mathrm{~g} / \mathrm{kg}$ EFPO groups, respectively.

\section{Histopathological analysis}

Hepatocytes in the EFPO groups showed clear structures, arranged radially along the central vein, and the hepatic sinusoid cavity was wider than that in the PH group. The 3.6 $\mathrm{g} / \mathrm{kg}$ EFPO group showed clearly widened hepatic sinusoid cavity, several enlarged nuclei, slightly ballooning degeneration of hepatocytes, and spotty and focal necrosis in portal area away from the central vein. Hepatic sinusoid cavities of 1.8 and $0.9 \mathrm{~g} / \mathrm{kg}$ EFPO groups were narrower, and hepatocytes were arranged more loosely than that in the $3.6 \mathrm{~g} / \mathrm{kg}$ EFPO group. The liver organization structure in the CTX group was quite damaged, showed a widened hepatic sinusoid cavity, significant ballooning degeneration of hepatocytes, and several anuclear hepatocytes (Figure 2).

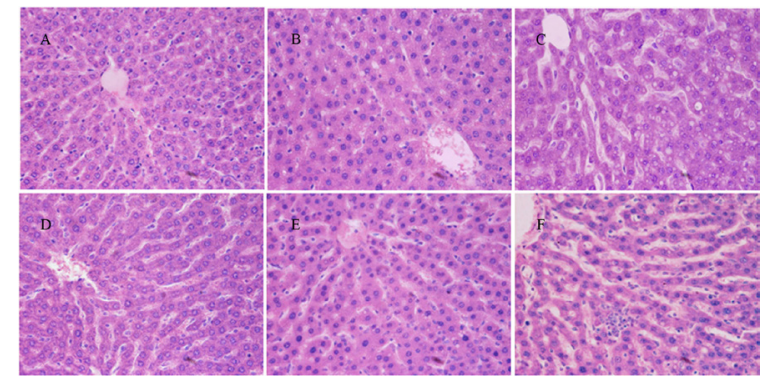

Figure 2. Effect of fructus polygoni orentalis extract (EFPO) on liver tissue structure of rat (400X). Hepatocytes in the EFPO groups had clear structures, were arranged radially along the central vein, and the hepatic sinusoid cavity was wider than that in the partial hepatectomy $(\mathrm{PH})$ group. $\mathrm{A}, \mathrm{B}, \mathrm{C}, \mathrm{D}, \mathrm{E}$, and $\mathrm{F}$ represent the sham operation (SO), control, cyclophosphamide (CTX), and 0.9, 1.8, and $3.6 \mathrm{~g} / \mathrm{kg}$ EFPO groups, respectively. 


\section{BMC morphology and proliferation}

Marrow cavity hyperemia and loosened and dark red tissue were observed in the $3.6 \mathrm{~g} /$ $\mathrm{kg}$ EFPO and CTX groups, while a full marrow cavity and bright red tissue were observed in the $\mathrm{SO}$ and control groups. The 1.8 and $0.9 \mathrm{~g} / \mathrm{kg}$ EFPO groups showed looser and lighter red tissue than the control group, which was fuller and darker than the CTX group (data not shown).

The results of G-R staining are shown in Figure 3. The BMC karyocyte clearly increased, and very few mature erythrocytes were observed in the control group. Karyocyte decreased, and mature erythrocytes increased in a dose-dependent manner $(\mathrm{P}<0.05)$ in the EFPO groups. No obvious difference was observed between the $\mathrm{SO}$ and control groups. The control and $\mathrm{SO}$ groups exhibited myeloproliferative activity in the bone marrow. The EFPO groups inhibited myelosis in a dose-dependent manner compared to the control group (Figure 3).

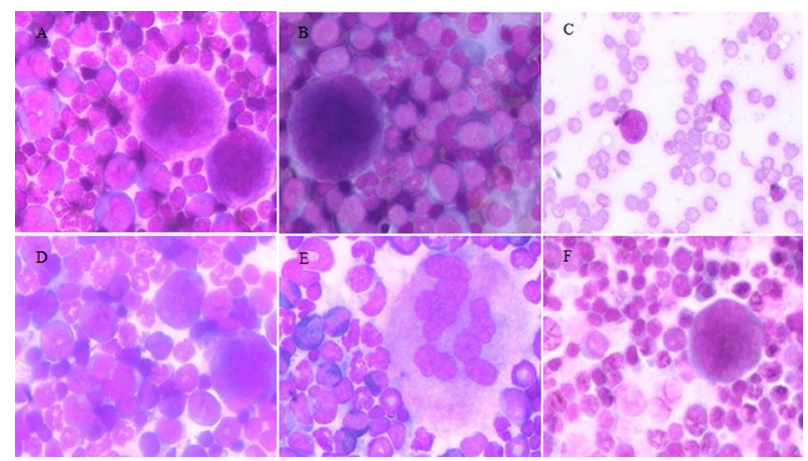

Figure 3. Morphology of bone marrow cells (BMCs;1000X). Karyocyte decreased, and mature erythrocytes increased in a dose-dependent manner in the fructus polygoni orentalis extract (EFPO) groups observed by G-R (Giemsa-Wright) staining. A, B, C, D, E, and $\mathbf{F}$ represent the sham operation (SO), control, cyclophosphamide (CTX), and $0.9,1.8$, and $3.6 \mathrm{~g} / \mathrm{kg}$ EFPO groups, respectively.

The expression of PCNA (Figure 4) in BMCs in the 1.8 and $3.6 \mathrm{~g} / \mathrm{kg}$ EFPO groups was lower than that in the control group $(\mathrm{P}<0.05)$. This implied that $\mathrm{PH}$ had no obvious impact on $\mathrm{BMC}$ proliferation $(\mathrm{P}>0.01)$, and that 1.8 and $3.6 \mathrm{~g} / \mathrm{kg}$ EFPO significantly inhibited the proliferation of BMCs compared with the $\mathrm{PH}$ and $\mathrm{SO}$ groups $(\mathrm{P}<0.01)$.

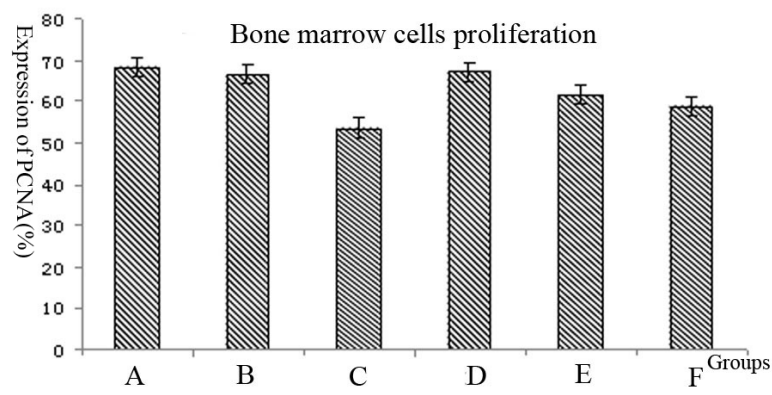

Figure 4. Effect of fructus polygoni orentalis extract (EFPO) on bone marrow cell (BMC) proliferation in partial hepatectomy $(\mathrm{PH})$ rats. $\mathrm{PH}$ had no obvious impact on the proliferation of BMCs, and 1.8 and $3.6 \mathrm{~g} / \mathrm{kg} \mathrm{EFPO}$ significantly inhibited the proliferation of BMCs. A, B, C, D, E, and F represents the sham operation (SO), control, cyclophosphamide (CTX), and 0.9, 1.8, and 3.6 g/kg EFPO groups, respectively. 


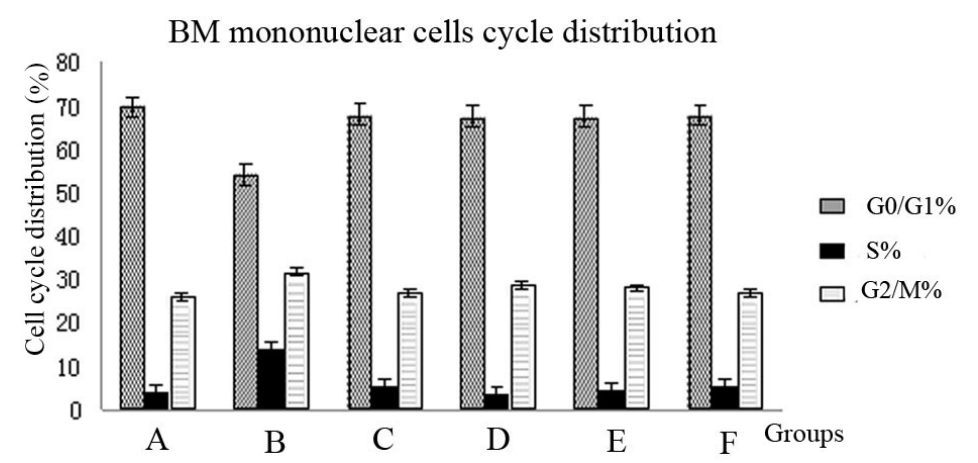

Figure 5. Effect of fructus polygoni orentalis extract (EFPO) on the cell cycle distribution of bone marrow mononuclear cells in partial hepatectomy $(\mathrm{PH})$ rats. PH induced bone marrow mononuclear cell proliferation, while EFPO inhibited bone marrow mononuclear cell proliferation after PH. A, B, C, D, E, and F represent the sham operation (SO), control, cyclophosphamide (CTX), and 0.9, 1.8, and 3.6 g/kg EFPO groups, respectively.

\section{Effect of EFPO on cell cycle distribution of BMC}

Cell cycle experiments (Figure 5) showed that the proportion of $\mathrm{G}_{2} / \mathrm{M}$ and $\mathrm{S} \%$ bone marrow mononuclear cells in $\mathrm{PH}$ rats were higher than that in the SO group $(\mathrm{P}<0.01)$. After administration for 7 days, the proportion of $\mathrm{G}_{\mathrm{o}} / \mathrm{G} 1 \%$ in the CTX and EFPO groups were increased compared to that in the control group $(\mathrm{P}<0.01)$.

\section{Maximum dosage}

Compared to control mice, clear postmortem differences were not observed in the EFPO groups. Thus, the maximum dosage of administration ig is $148.8 \mathrm{~g} / \mathrm{kg}$, which is 89.3 fold of the adult oral administration dosage per day.

\section{DISCUSSION}

Recently, plants used in folk medicine have been accepted as the main sources of drug discovery and development. In China, Traditional Chinese Medicines (TCMs) represent a very large reservoir of plants with tremendous diversity. Fructus polygoni orientalis has been used to treat liver disease in China, with a total cirrhosis effective rate of $90.3 \%$. The negative conversion ratio of HBsAg was 59\%, and 1-year survival rate for hepatocarcinogens was $60 \%$ in combination with other herbs as reported by TCM practitioners.

Advances in molecular techniques over the past few decades have resulted in the development of regenerative medicine methods. Liver regeneration in response to different types of liver injury such as drugs, toxins, resection, or acute viral diseases has been examined in numerous studies (Fausto, 2006; Riehle et al., 2011). A detailed understanding of cell proliferation in response to injury will be applicable to other organ dysfunctions (Yamazaki et al., 2011), and may also shed light on how cancer, cirrhosis, and other liver disease pathogenesis develops, can be treated, and is repaired after PH (Hixson et al., 2000). Thus, liver regeneration and PH rat models have been used extensively to explore regeneration mechanisms, liver disease pathogenesis, and drug screening. In our study, we explored the effect of EFPO extract 
on PH rats, and we found that EFPO inhibited liver cell proliferation in a concentration-dependent manner, increased body weight loss, and delayed liver repair. We provided a theoretical basis for using fructus polygoni orientalis to treat liver diseases.

With the increasing identification of TCM and development of technology, the toxicity and side effects of TCMs has caused widespread concern. Our preliminary experiments showed that EFPO inhibited mononuclear phagocyte activity and T- and B-lymphocyte transformation rate, as well as decreased the proportion of T-lymphocyte in the peripheral blood and suppressed the secretion of IgM in normal Kunming mice. To determine whether EFPO could also inhibit the immune function during liver regeneration in rats, we explored bone marrow function in $\mathrm{PH}$ rats. The results showed that EFPO inhibited PCNA expression of BMCs in PH rats, accumulated in the BM mononuclear cells during the $\mathrm{G}_{\mathrm{O}} / \mathrm{G}_{1}$ phases, clearly decreased the karyocyte of BMCs, and increased mature erythrocytes. These results were in agreement with those of some studies examining immunosuppressive agents of TCMs (Kato et al., 1994; Nagy et al., 1997; Cho et al., 2000; Kang et al., 2000; Krakauer et al., 2001). Numerous TCMs have been applied to treat liver diseases and studied for their ability to limit the progression of liver diseases by improving immunological function (Agrawal et al., 2008; Lee et al., 2012).

In conclusion, EFPO inhibited liver regeneration and liver repair after PH in rats, and inhibited bone marrow function at the same dosage, which was slightly higher than CTX. Whether the suppression of bone marrow induced by EFPO can be prevented by TCMs should be further examined.

\section{ACKNOWLEDGMENTS}

Research supported by the Foundation and Advancing Program of Henan Province (\#122300410253).

\section{REFERENCES}

Agrawal A, Sharma M, Rai SK, Singh B, et al. (2008). The effect of the aqueous extract of the roots of Asparagus racemosus on hepatocarcinogenesis initiated by diethylnitrosamine. Phytother. Res. 22: 1175-1182.

Bautista-Ortín AB, Fernández-Fernández JI, López-Roca JM and Gómez-Plaza E (2007). The effects of enological practices in anthocyanins, phenolic compounds and wine colour and their dependence on grape characteristics. $J$. Food Composit. Anal. 20: 546-552.

Cho JY, Baik KU, Jung JH and Park MH (2000). In vitro anti-inflammatory effects of cynaropicrin, a sesquiterpene lactone, from Saussurea lappa. Eur. J. Pharmacol. 398: 399-407.

Fausto N (2006). Involvement of the innate immune system in liver regeneration and injury. J. Hepatol. 45: 347-349.

Higgins GM and Anderson RM (1931). Experimental pathology of the liver: restoration of the liver of the white rat following partial surgical removal. Arch. Pathol. 12: 186-202.

Hixson DC, Brown J, McBride AC and Affigne S (2000). Differentiation status of rat ductal cells and ethionine-induced hepatic carcinomas defined with surface-reactive monoclonal antibodies. Exp. Mol. Pathol. 68: 152-169.

Kang TH, Pae HO, Yoo JC, Kim NY, et al. (2000). Antiproliferative effects of alkaloids from Sedum sarmentosum on murine and human hepatoma cell lines. J. Ethnopharmacol. 70: 177-182.

Kato M, Pu MY, Isobe K, Iwamoto T, et al. (1994). Characterization of the immunoregulatory action of saikosaponin-d. Cell Immunol. 159: 15-25.

Krakauer T, Li BQ and Young HA (2001). The flavonoid baicalin inhibits superantigen-induced inflammatory cytokines and chemokines. FEBS Lett. 500: 52-55.

Kuroyanagi M and Fukushima S (1982). Highly oxygenated flavonoids from Polygnum orientale. Chem. Pharmaceut. Bull. 30: 1163-1168.

Lee CK, Park KK, Chung AS and Chung WY (2012). Ginsenoside Rg3 enhances the chemosensitivity of tumors to cisplatin by reducing the basal level of nuclear factor erythroid 2-related factor 2-mediated heme oxygenase-1/NAD(P)H 
quinone oxidoreductase-1 and prevents normal tissue damage by scavenging cisplatin-induced intracellular reactive oxygen species. Food Chem. Toxicol. 50: 2565-2574.

Makris DP, Boskou G and Andrikopoulos NK (2007). Polyphenolic content and in vitro antioxidant characteristics of wine industry and other agri-food solid waste extracts. J. Food Composit. Anal. 20: 125-132.

Nagy L, Kao HY, Chakravarti D, Lin RJ, et al. (1997). Nuclear receptor repression mediated by a complex containing SMRT, mSin3A, and histone deacetylase. Cell 89: 373-380.

Riehle KJ, Dan YY, Campbell JS and Fausto N (2011). New concepts in liver regeneration. J. Gastroenterol. Hepatol. 26 (Suppl. 1): 203-212.

The Editorial Committee of 'Zhong Hua Ben Cao', State Administration of Traditional Chinese Medicine of People's Republic of China (1999). Zhong Hua Ben Cao. Shanghai Science and Technology Publisher. Shanghai, 1323.

Tu YC, Lian TW, Yen JH, Chen ZT, et al. (2007). Antiatherogenic effects of kaempferol and rhamnocitrin. J. Aqric. Food Chem. 28: 9969-9976.

Xie ZT, He ZA and Liu YW (2005). Progress of chemical composition and pharmacological research about Polygonum orientale L (Chin.). Lishizhen Med. Mater. Med. Res. 10: 874-876.

Yamazaki Y, Moore R and Negishi M (2011). Nuclear receptor CAR (NR1I3) is essential for DDC-induced liver injury and oval cell proliferation in mouse liver. Lab. Invest. 91: 1624-1633. 